\title{
Theoretical study on the formation mechanism of pre-intermediates for PXDD/Fs from 2-Bromophenol and 2-Chlorophenol precursors via

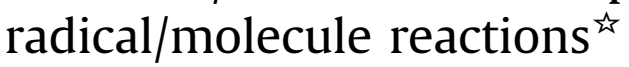

\author{
Wenxiao Pan ${ }^{\text {a }}$, Jianjie $\mathrm{Fu}^{\mathrm{a}, \mathrm{b}}$, Aiqian Zhang ${ }^{\mathrm{a}, \mathrm{b},{ }^{*}}$ \\ a State Key Laboratory of Environmental Chemistry and Ecotoxicology, Research Center for Eco-Environmental Sciences, Chinese Academy of Sciences, \\ Beijing 100085, PR China \\ ${ }^{\mathrm{b}}$ College of Resources and Environment, University of Chinese Academy of Sciences, Beijing 100190, PR China
}

\section{A R T I C L E I N F O}

\section{Article history:}

Received 21 October 2016

Received in revised form

13 February 2017

Accepted 2 March 2017

Available online 14 March 2017

\section{Keywords:}

PXDD/Fs

Formation mechanism

Radical/molecule reactions

DFT study

\begin{abstract}
A B S T R A C T
This study investigates reaction pathways for the formation of pre-PXDD/F intermediates via a radical/ molecule mechanism. Thermodynamic and kinetic parameters for the combination reactions of 2bromophenol (2-BP) and 2-chlorophenol (2-CP) precursors with key radical species including the phenoxy radicals, the phenyl radicals and the phenoxyl diradicals were calculated in detail. The couplings of phenoxy radicals with $2-\mathrm{B}(\mathrm{C}) \mathrm{P}$ tend to produce pre-PXDD intermediates of halogenated 0 -phenoxyphenol. The combinations of phenyl and phenoxyl diradicals with 2-B(C)P produce two types of structures, i.e., dihydroxybiphenyl and o-phenoxyphenyl, which exclusively act as prestructures of PXDFs. These condensation reactions, especially those involving the phenyl $\mathrm{C}$ atom sites in phenyl and phenoxyl diradicals, are proven to be both thermodynamically and kinetically favorable and are nearly comparable with the corresponding steps involved in the radical/radical reactions. Most importantly, reactions of phenyl and phenoxyl diradicals with halogenated phenols solely lead to the formation of PXDFs, which to some extent provides a plausible explanation for the high PXDF-to-PXDD ratios in the real environment. Therefore, our study reveals the pivotal role of the radical/molecule mechanism in homogeneous gas-phase PXDD/F formation, especially in PXDF formation. The present results fill in a knowledge gap that has hitherto existed regarding dioxin formation and improve our understanding of $\mathrm{PXDD} / \mathrm{F}$ formation characteristics in the environment.
\end{abstract}

(c) 2017 Elsevier Ltd. All rights reserved.

\section{Introduction}

Polychlorinated dibenzo-p-dioxins/dibenzofurans (PCDD/Fs) are well-known environmental pollutants that are strongly linked to extremely high toxicity, carcinogenicity, and bioaccumulation potential. Polybrominated dibenzo-p-dioxins/dibenzofurans (PBDD/Fs) and mixed polybrominated/chlorinated dibenzo-pdioxins/dibenzofurans (PXDD/Fs) are PCDD/F analogues in which the chlorine atoms in PCDD/Fs are totally and partially substituted by bromine atoms, respectively. Due to the structural similarity, PBDD/Fs and PXDD/Fs possess eco-toxicological and toxicological

\footnotetext{
This paper has been recommended for acceptance by Kimberly Hageman.

* Corresponding author. State Key Laboratory of Environmental Chemistry and Ecotoxicology, Research Center for Eco-Environmental Sciences, Chinese Academy of Sciences, Beijing 100085, PR China.

E-mail address: aqzhang@rcees.ac.cn (A. Zhang).
}

properties quite similar to their chlorinated counterparts; thus, both chemical categories pose a severe threat to human health and the environmental safety (Samara et al., 2009; Olsman et al., 2007). All these chemicals have never been intentionally synthesized in industrial processes (Du et al., 2010; Söderström and Marklund, 2002). While a deep insight into the formation mechanism of PXDD/Fs is of importance, as it can serve as a basis for minimizing or even eliminating dioxin emissions.

Two general pathways including de novo synthesis and precursor route were proposed to account for the formation of PXDD/Fs (Altarawneh et al., 2009b; Weber and Kuch, 2003). The former one refers to the combination reactions origining from elemental carbon, oxygen, hydrogen, and chlorine catalyzed by typical transition metals in the temperature region of $200-400{ }^{\circ} \mathrm{C}$ (Stieglitz, 1998). While the latter involves reactions of numbers of precursors such as chlorinated phenols, chlorobenzenes and several large molecular pesticides occurring both on the transition metal-contained fly ash 
surfaces in lower temperature windows of $200-400{ }^{\circ} \mathrm{C}$ and in the gas-phase at higher temperatures $\left(>600{ }^{\circ} \mathrm{C}\right.$ ) (Altarawneh et al., 2008; Altarawneh et al., 2009a). A general trend with PXDFs as dominant emission products has been observed in waste incinerators and some industrial processes such as secondary copper production and iron ore sintering etc (Du et al., 2010; Duan et al., 2011; Li et al., 2015; Wang et al., 2015; Xiao et al., 2016). Earlier studies indicated that de novo synthesis generates more PXDFs than PXDDs (Ryan and Altwicker, 2004). The studies performed by Luijk et al. (1994) and Ryan and Altwicker. (2004) proposed that PCDDs with more oxygen atoms (ether bridges) are more prone to oxidation degradation than PCDFs which may result in higher PCDF to PCDD ratios in the de novo synthesis process. Although the de novo synthesis was generally taken as a common interpretation that in the incinerator systems where PXDFs are major polyhalogenated dioxin products (Ortuno et al., 2014), in fact, apart from the de novo corridors, precursor routes also yield more PXDFs than PXDDs. For instance, Ryu et al. (2005) investigated the homologue patterns of $\mathrm{PCDD} / \mathrm{Fs}$ from chlorophenol condensation reactions, and the results suggest that the PCDF-to-PCDD molar ratio was approximately 200 and 3 in the gas-phase and particlemediated experiments, respectively. More PCDFs were attributed to the homogenous reactions (Ryu et al., 2005). Moreover, the precursor pathway was reported to be approximately $10^{2}-10^{5}$ times faster than the de novo synthesis (Altwicker and Milligan, 1993; Dickson et al., 1992). Accordingly, the precursor route, especially the gaseous reactions, may contribute greatly to the high PXDF-to-PXDD ratios in environmental samples.

Chlorophenols (CPs) and bromophenols (BPs), potent and direct precursors of $\mathrm{PXDD} / \mathrm{Fs}$, are among the most abundant aromatic compounds in the incinerator gas emissions (Evans and Dellinger, 2005; 2006). Two reaction patterns including radical/radical and radical/molecule combinations were proposed to account for the homogeneous gas-phase formation of PXDD/Fs from CPs and BPs. Consensus of opinion in the literature indicates that the radical/ radical mechanism bears more importance than the radical/molecule mechanism, and the contribution of the latter has long been overlooked (Louw and Ahonkhai, 2002; Sidhu and Edwards, 2002). For the formation of PCDD/Fs, the radicals involved include chlorophenoxy radicals, chloro- and hydroxyl-substituted phenyl radicals, and chlorinated phenoxyl diradicals (also called chlorinated $\alpha$ ketocarbene), which are important intermediates (Lomnicki et al., 2008; Pan et al., 2013; Zhang et al., 2014). Similarly, bromophenoxy radicals play an important role in the formation of PBDD/Fs and PXDD/Fs (Saeed et al., 2015; Shi et al., 2015). As far as we know, there is no research available pertinent to bromo- and hydroxylsubstituted phenyl radicals or brominated phenoxyl diradicals. However, by analogy to the chlorinated systems, it is reasonable to assume that the brominated phenyl radicals and phenoxyl diradicals follow similar pathways to form PBDD/Fs and PXDD/Fs.

The most discussed radical/radical mechanism is composed of self-/cross-combinations of these above-mentioned radical species. However, previous research on the gas-phase formation mechanism indicates that dioxins rather than furans are the favored products in the radical/radical combination reactions (Yasuharu and Mutsumi, 1999; Zhang et al., 2008), which is in stark contrast to the experimental observations that furans are the main products. In other words, the existing radical/radical mechanism cannot make a full explanation on the known fact that PXDFs are predominant products in gas-phase reactions. As stated, this significant discrepancy has implications for the possible involvement of other routes under high temperature conditions, for instance, the radical/molecule mechanism. A careful examination of the literature shows that previous radical/molecule mechanism studies exclusively considered the reactions of $\mathrm{BP} / \mathrm{CP}$ molecules with the halogenated phenoxy radicals. Early studies suggested that the reactions might be hindered due to the energetically unfavorable halogen or hydroxyl displacement steps in the initial reactions between $\mathrm{BP} / \mathrm{CPs}$ and halogenated phenoxy radicals (Louw and Ahonkhai, 2002). For this reason, the contribution of the radical/ molecule mechanism has long been overlooked to total PXDD/F emissions. As far as we know, however, so far, there are no available studies on the possible combination reactions of $\mathrm{BP} / \mathrm{CPs}$ with substituted phenyl and phenoxyl diradicals. We therefore turn our attention to the above-mentioned condensation reactions for the following reasons. First, phenyl and phenoxyl diradicals have great potential to form dioxins (Pan et al., 2013; Zhang et al., 2014). Second, both the phenyl and phenoxyl diradicals have a typical $\sigma$ type radical center that possesses high reactivity and therefore are likely to react with $\mathrm{CP}$ and $\mathrm{BP}$ molecules readily. Third, exclusive PCDF formation by chlorinated benzenes may be strongly correlated with the reactions of phenyl carbon radicals that afford high PXDF-to-PXDD ratios (Nganai et al., 2011; 2014).

In this work, using 2-bromophenol (2-BP) and 2-chlorophenol (2-CP) as model compounds, we investigated the initial pathways for the gas phase formation of PXDD/Fs through the condensation reactions of 2-BP/2-CP with substituted phenyl radical 2hydroxylphenyl (PR2), 2-hydroxyl-3-bromo-phenyl (BPR2) and 2hydroxyl-3-chloro-phenyl (CPR2), phenoxyl diradical (PR3), substituted phenoxyl diradicals 3-bromo-2-oxocyclohexa-2,5dienylidene (BPR3) and 3-chloro-2-oxocyclohexa-2,5-dienylidene (CPR3) (shown in Fig. 1). The objective of this work is to explore new mechanisms for the formation of PXDD/Fs and determine the effect of these two types of radicals on the resulting PXDF-to-PXDD ratio. The optimized structures of the molecules and radicals involved in this work are depicted in Fig. 1.

\section{Computational methods}

All of the electronic structure calculations were conducted using the Gaussian 09 program suite (Frisch et al., 2010). Fully geometrical optimizations for the reactants, intermediates, and products involved in this work were conducted using the BB1K functional with the standard 6-311G(d,p) basis set. The vibrational frequencies were calculated at the same level of theory to determine the nature of minima and first-order saddle points and to provide the zeropoint vibrational enthalpy $(\mathrm{ZPH})$. Single point energy calculations were refined at the BB1K/6-311+G (3df,2p) level. The BB1K functional performs well on saddle point geometry and barrier height calculations and has been successfully used in previous dioxin formation studies (Pan et al., 2013; Zhao et al., 2004). Calculations of the intrinsic reaction coordinate (IRC) were performed to confirm that each transition state (TS) is connected to the two desired minima. Furthermore, as will be seen in the following section, the geometries of the intermediates and transition state structures involved in the reactions of $2-\mathrm{B}(\mathrm{C}) \mathrm{P}$ molecule with $\mathrm{H}$ radical were optimized at the $\mathrm{BB} 1 \mathrm{~K}$ and M06-2X functional combined with the standard $6-311 \mathrm{G}(\mathrm{d}, \mathrm{p})$, def-TZVP, and aug-cc-pVDZ basis sets, and the corresponding activation and reaction enthalpies were also calculated in order to indentify the reliability and accuracy of the method adopted in this work.

The kinetic calculations were carried out using the kinetic and statistical thermodynamic (KiSThelP) program (Canneaux et al., 2014). The reaction rate constants for all the radical/molecule combination reactions were calculated based on the conventional transition state theory (TST) over the temperature range of $600-1200 \mathrm{~K}$. The effect of quantum tunneling on rate constants was considered based on the one-dimensional Wigner's formalism as implemented in the KiSThelP program (Wigner, 1937). Pressuredependent reaction rate constants for several unimolecular 


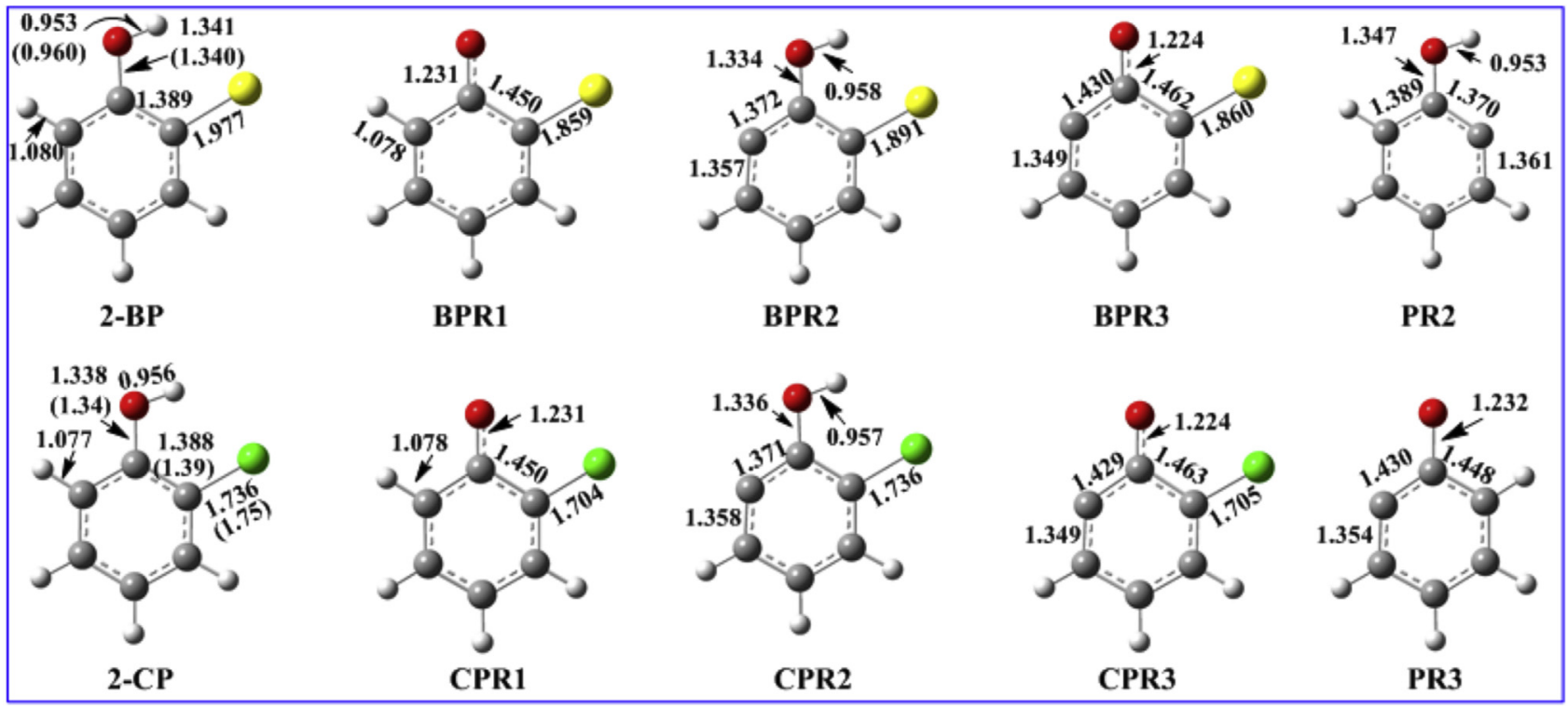

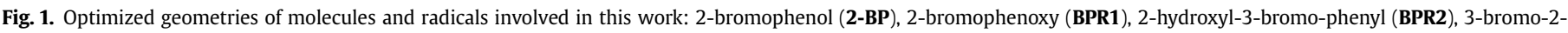

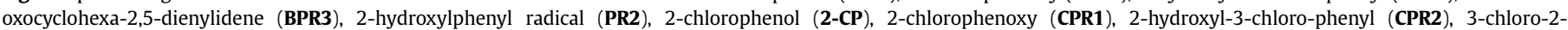

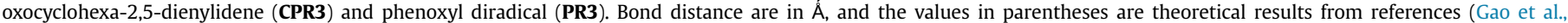

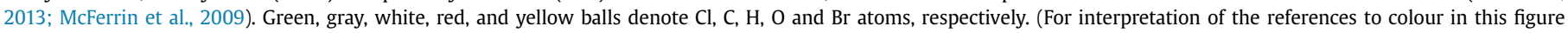
legend, the reader is referred to the web version of this article.)

reactions were evaluated based on the microcanonical RiceRamsperger-Kassel-Marcus (RRKM) theory (Klippenstein, 2003). Nitrogen was chosen as the bath gas to simulate intermediate collisions and we set the Lennard-Jones parameters for the reactive species to $\sigma=7.0 \AA$ and $k / \varepsilon_{\mathrm{b}}=500.0 \mathrm{~K}$ (Altarawneh and Dlugogorski, 2015a).

\section{Results and discussion}

Both 2-BP and 2-CP molecules exhibit two distinct geometries depending on whether the hydroxyl $\mathrm{H}$ atom is close or far away from the ortho-substituted halogen atom, which are denoted as syn- and anti-structures, respectively. Due to the intramolecular hydrogen bonding between the hydroxyl $\mathrm{H}$ atom and the orthosubstituted halogen atom, the syn-conformer is approximately $3 \mathrm{kcal} / \mathrm{mol}$ more stable than the anti-one. Thus, throughout this paper, 2-BP and 2-CP denote the syn-conformers.

In order to set a benchmark for the accuracy of the adopted methodology, we firstly made a comparison on the geometrical parameters of 2-B(C)P with the available theoretical results in literatures. As shown in Fig. 1, the calculated results at the BB1K/6$311 \mathrm{G}(\mathrm{d}, \mathrm{p})$ level are in good agreement with the reference values. In addition to the geometrical characteristics, the bond dissociation enthalpies (BDHs) for aromatic $\mathrm{C}-\mathrm{Cl}, \mathrm{C}-\mathrm{Br}$, and phenolic $\mathrm{O}-\mathrm{H}$ bonds calculated at the BB1K/6-311+G(3df,2p)//BB1K/6-311G (d,p) level are estimated to be $99.3,85.4$, and $88.3 \mathrm{kcal} / \mathrm{mol}$, respectively, which concur well with the corresponding experimental values of $95.5 \pm 1.5,83.5 \pm 2.5$, and $87.3 \mathrm{kcal} / \mathrm{mol}$, separately (Luo, 1999).

\subsection{Formation of radical species $P R 2, P R 3$, and $B(C) P R 1-B(C) P R 3$ from 2-BP and 2-CP molecules}

As can be seen in Fig. 1, from a chemical point of view, the halogen-substituted phenoxy radical B(C)PR1 arises from direct fission of the $\mathrm{O}-\mathrm{H}$ bond from $2-\mathrm{B}(\mathrm{C}) \mathrm{P}$, while the phenyl radicals PR2 and $\mathbf{B}(\mathbf{C}) \mathbf{P R} 2$ stem from expulsion of the halogen $(\mathrm{Br}$ or $\mathrm{Cl})$ or $\mathrm{H}$ atom bound to the carbon located next to the hydroxyl group. The diradical PR3 and B(C)PR3 are characterized by loss of both the hydroxyl $\mathrm{H}$ and the ortho substituted halogen $(\mathrm{Br}$ or $\mathrm{Cl})$ or $\mathrm{H}$ atom. These radicals may form via $\mathrm{H}$ - or halogen-abstraction reactions of $2-\mathrm{B}(\mathrm{C}) \mathrm{P}$ with various active radicals, such as $\mathrm{H}, \mathrm{OH}, \mathrm{O}\left({ }^{3} \mathrm{P}\right)$ and $\mathrm{Cl}$, that are abundant in the combustion environment. In this section, we investigate their formation from the reactions of $2-B(C) P$ with atomic $\mathrm{H}$, as detailed in Fig. 2 . The reaction and activation enthalpy values involved in each step are also given in Fig. 2. It should be noted that formation of CPR1-CPR3 assisted by atomic $H$ has been investigated by Zhang et al. (2014). For the sake of completeness and comparison, we calculated the corresponding reaction pathways again and the results are listed in Fig. $2 \mathrm{~b}$.

As illustration in Fig. 2, formation of the substituted phenoxy radicals $\mathbf{B}(\mathbf{C}) \mathbf{P R} 1$ and the substituted phenyl radicals $\mathbf{B}(\mathbf{C}) \mathbf{P R} 2$ occurs through hydroxyl-H and ortho- $\mathrm{H}$ abstraction from $2-\mathrm{B}(\mathrm{C}) \mathrm{P}$ molecules, respectively. A subsequent abstraction of the hydroxyl$\mathrm{H}$ from $\mathbf{B}(\mathbf{C}) \mathbf{P R 2}$ or the ortho-substituted $\mathrm{H}$ from $\mathbf{B}(\mathbf{C}) \mathbf{P R} 1$ results in the production of the substituted phenoxyl diradicals $\mathbf{B}(\mathbf{C}) \mathbf{P R} 3$. From careful inspection of the thermodynamic values embedded in Fig. 2, we find that the activation enthalpies involved in these reaction corridors fall within a $11.6-17.0 \mathrm{kcal} / \mathrm{mol}$ window, which might be readily overcome under high temperature conditions. Additionally, the Br-abstraction by $\mathrm{H}$ from 2-BP and BPR1 leading to the formation of phenyl radical PR2 and phenoxyl diradical PR3 are found to require activation enthalpies of 7.9 and $7.5 \mathrm{kcal} / \mathrm{mol}$, respectively. Apparently, the Br-abstraction process is much easier to take place with respect to the aromatic $\mathrm{H}$ abstraction process, which is in line with the corresponding $\mathrm{BDH}$ of aromatic $\mathrm{C}-\mathrm{Br}$ and C-H, i.e., 85.4 and $88.3 \mathrm{kcal} / \mathrm{mol}$, correspondingly. Similarly, abstractions of $\mathrm{Cl}$ from 2-CP and CPR1 can also generate PR2 and PR3 with activation enthalpies of 13.8 and $13.6 \mathrm{kcal} / \mathrm{mol}$, respectively. Thus the pristine and substituted radical species PR2, PR3 and B(C) PR1-B(C)PR3 can be easily formed in combustion systems. Moreover, due to the structural similarity between 2-BP and 2-CP, the reaction and activation enthalpies involved in each corresponding reaction step for brominated and chlorinated pathways are found to be quite comparable. For instance, the activation 


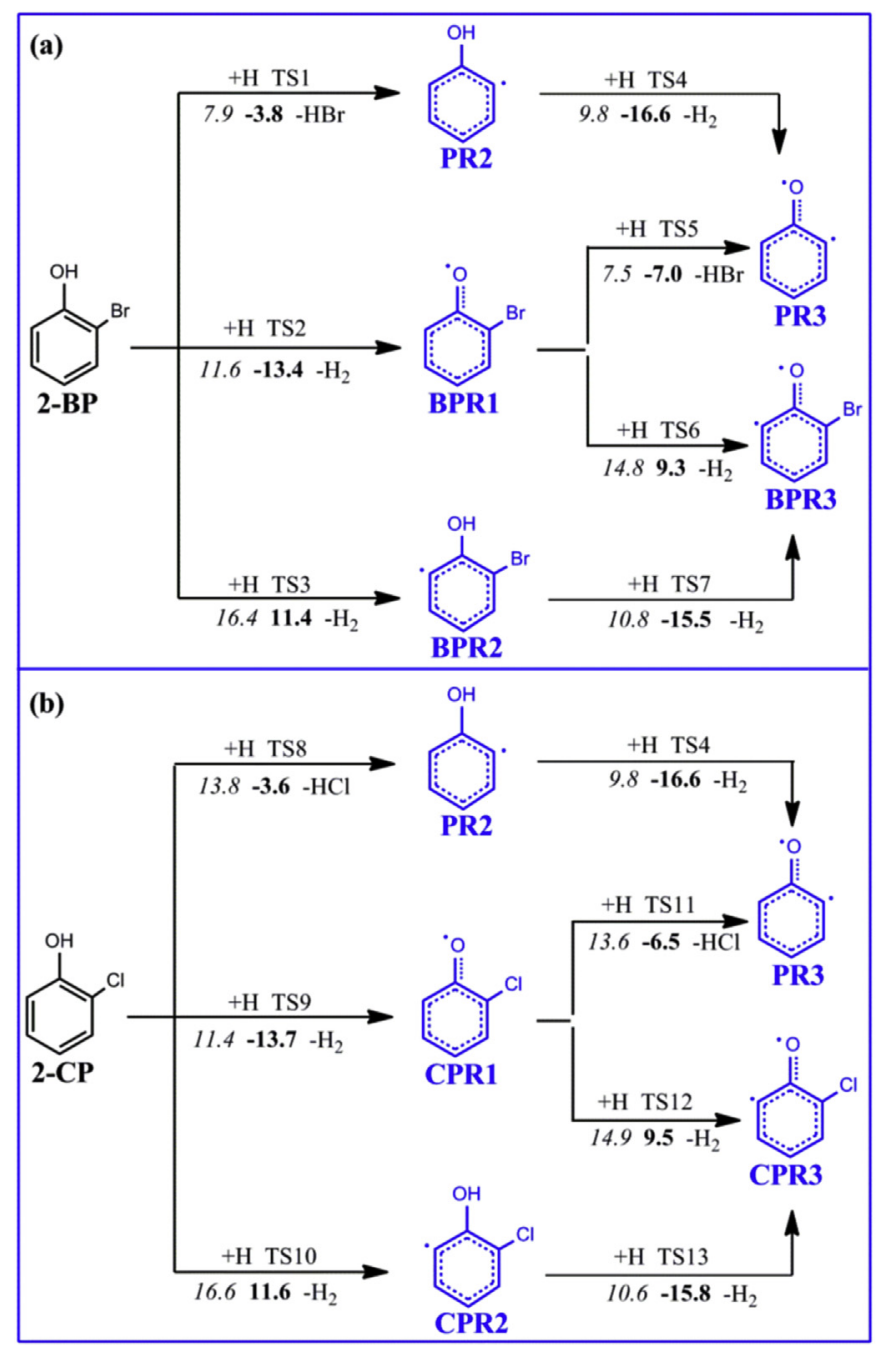

Fig. 2. Formation of pristine and substituted radical species PR2, PR3 and BPR1-BPR3 from reactions of 2-BP (a) and 2-CP (b) with $\mathrm{H}$ radicals, respectively. Values in bold are reaction enthalpies, and values in italic are activation enthalpies in reference to the reactants in each reaction. All values are in $\mathrm{kcal} / \mathrm{mol}$ at $298.15 \mathrm{~K}$.

enthalpies involved in the hydroxyl $\mathrm{H}$-abstraction reactions from 2$\mathrm{BP}$ and $2-\mathrm{CP}$ are 11.6 and $11.4 \mathrm{kcal} / \mathrm{mol}$, respectively. This fact suggests that the formation of brominated radical species from 2-BP molecule is energetically comparable with that for the chlorinated counterparts from 2-CP molecule. Furthermore, the result obtained herein indicates that these radical species may arise in the same temperature window and thus provides great possibility for effective collisions between these radical species and the radicals with molecules.

For further identification the reliability and accuracy of the method adopted in this work, we compared the activation $(\Delta E)$ and reaction $(\Delta H)$ enthalpies involved in the formation of these radical species calculated at the BB1K/6-311+G(3df,2p)//BB1K/6311G(d,p), BB1K/def2-TZVP, BB1K/aug-cc-pVDZ, M06-2X/6311+G(3df,2p)//M06-2X/6-311G(d,p), M06-2X/def2-TZVP, M062X/aug-cc-pVDZ levels, respectively, and the results are listed in Table S1. Inspection of the data in Table $\mathrm{S} 1$, we can see that the $\Delta E$ and $\Delta H$ calculated at these six methods are in good agreement, that is, the maximum differences in $\Delta E$ and $\Delta H$ are 2.0 and $4.1 \mathrm{kcal} / \mathrm{mol}$, respectively. The absolute average difference of the $\mathrm{BB} 1 \mathrm{~K} / 6-$ $311+\mathrm{G}(3 \mathrm{df}, 2 \mathrm{p}) / / \mathrm{BB} 1 \mathrm{~K} / 6-311 \mathrm{G}(\mathrm{d}, \mathrm{p})$ methods with other five methods for $\Delta E$ and $\Delta H$ are 0.6 and $1.9 \mathrm{kcal} / \mathrm{mol}$, respectively. Based on these results, we can see that the six investigated methods generate comparable energetics, and then we continue to use the BB1K/6-311+G(3df,2p)//BB1K/6-311G(d,p) method in the following radical/molecule combination calculations.

\subsection{Reactive sites of radical species}

To gain insight into reactive sites of these radical species, the spin density analyses were performed. The corresponding spin density profiles are shown in Fig. 3, with yellow and blue colors representing positive and negative densities, respectively. It should be noted that, each corresponding pristine and substituted radical species, i.e., BPR1 and CPR1, PR2, BPR2 and CPR2, as well as PR3, BPR3 and CPR3 display very similar geometrical features (Fig. 1), which indicate that these radicals would also exhibit high similarity in their electronic structures and reactive properties (see the next section). As seen from Fig. 3, the unpaired spin density in B(C)PR1 is delocalized, and the radical character appears at the phenolic oxygen, the ortho carbon bearing a hydrogen or halogen atom, and the para carbon bonded to a hydrogen atom. Such a resonance property results in a delocalization energy of $16 \mathrm{kcal} / \mathrm{mol}$ so that B(C)PR1 can build up in considerable concentration to form dioxin compounds. For PR2 and B(C)PR2, the spin density is evidently localized on the carbon atom where the $\mathrm{C}-\mathrm{X},(\mathrm{H}, \mathrm{Br}$ or $\mathrm{Cl})$ bond is broken. In fact, the pristine phenyl radical, has been well documented to possess exceptional reactivity due to the localization of the unpaired electron in a $\sigma$-type orbital at the $\mathrm{C}-\mathrm{H}$ cleavage site (Martinez et al., 2015). For this reason, phenyl and its derivatives can react promptly with other radicals and molecules once they are formed. In addition to acting as potent intermediates for the formation of dioxins, phenyl radicals are also key intermediates in the formation of polycyclic aromatic hydrocarbons (PAHs) (Comandini et al., 2012).

The phenoxyl diradicals PR3 and $\mathbf{B}(\mathbf{C}) \mathbf{P R 3}$, possessing two unpaired electrons, are identified to have a triplet ground state. In PR3 and $\mathbf{B}(\mathbf{C}) \mathbf{P R} 3$, the unpaired electron resulting from the fission of phenoxyl $\mathrm{O}-\mathrm{H}$ bond is delocalized in the $\mathrm{p}-\pi$ conjugation orbital which is perpendicular to the phenyl ring plane; while, the other one arising from the rupture of the $\mathrm{C}-\mathrm{X}(\mathrm{H}, \mathrm{Br}$ or $\mathrm{Cl})$ bond is localized in the $\mathrm{sp}^{2}$-orbital of the carbon atom to give a $\sigma$-type radical at the $\mathrm{C}-\mathrm{X}(\mathrm{H}, \mathrm{Br}$ or $\mathrm{Cl})$ cleavage site (Martinez et al., 2015). Interestingly, these two unpaired electrons in $\mathbf{P R 3}$ and $\mathbf{B}(\mathbf{C}) \mathbf{P R} 3$ are located in two non-degenerated SOMOs: one of the SOMOs is

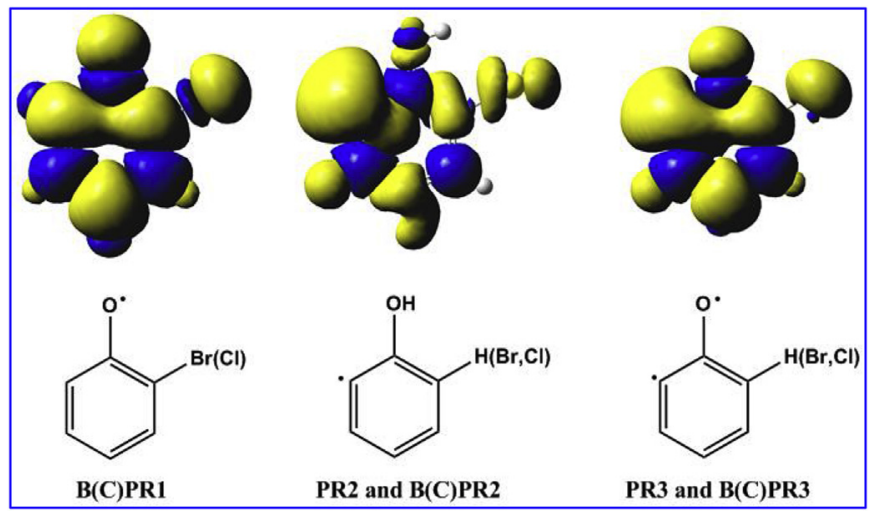

Fig. 3. Spin density contours (0.0004 e/au) (the upper row) and the corresponding structure configurations (the nether row) of pristine and substituted radical species PR2, PR3 and B(C)PR1 - B(C)PR3 calculated at BB1K/6-311G(d,p) level. Yellow and blue colors represent positive and negative spin densities, respectively. (For interpretation of the references to colour in this figure legend, the reader is referred to the web version of this article.) 
delocalized over the entire structure and the other is localized on the partial group or atoms. Similar phenomena have been reported by Kumai et al. (1994; 1996) on their studies of iron-radical species. The stability check of PR3 and B(C)PR3 were also carried out and demonstrated that the wave function is exactly a minimum in their triplet state. Seen from Fig. 3, the spin density distribution in PR3 and $\mathbf{B}(\mathbf{C}) \mathbf{P R} 3$ exhibits a characteristic of both $\mathbf{B}(\mathbf{C}) \mathbf{P R} 1$ and $\mathbf{B}(\mathbf{C}) \mathbf{P R 2}$, i.e., one unpaired electron is dramatically delocalized over the benzene ring of the radical, and the other one is localized on the phenyl $C$ atom. Accordingly, on the one hand, the conjugated structure offers stability towards PR3 and $\mathbf{B}(\mathbf{C}) \mathbf{P R} 3$, and on the other hand, the typical $\sigma$-type carbon radical center provides a highly reactive site. Although $\mathbf{B}(\mathbf{C}) \mathbf{P R} 3$ has not yet been identified in the combustion media, its prototype structure PR3 was observed by laser flash photolysis of 2-BP in aqueous solution, and this species has been proposed to be a possible intermediate for PCDD/Fs from the pyrolytic thermal degradation of catechol (Bonnichon et al., 2001; Lomnicki et al., 2008).

Condensations of 2-CP and 2-BP molecules with PR2, PR3 and B(C)R1-B(C)R3 will occur through all the identified reactive sites in these radicals. As the coupling pathways involving para carbons in these radicals with the para carbons in $2-\mathrm{B}(\mathrm{C}) \mathrm{P}$ are not relevant to the formation of PXDD/Fs, only the phenolic oxygen and the ortho carbon radical sites in $\mathbf{B}(\mathbf{C}) \mathbf{P R} 1$, the phenyl carbon centers in PR2, B(C)PR2 and B(C)PR3, and the phenolic oxygen in PR3 and B(C)PR3 are considered in the following radical/molecule coupling calculations.

\subsection{Formation of pre-intermediates of PXDD/Fs via radical/ molecule coupling reactions}

Coupling of radicals with radicals or molecules constitutes the initial and key step for the formation of PXDD/Fs. The radical/ molecule reaction pathways via combinations of $2-B(C) P$ molecule with pristine and substituted radical species PR2, PR3 and B(C) PR1-B(C)PR3 are depicted in Figs. 4-6. The values embedded in the reaction schemes in Figs. 4-6 are the activation and reaction enthalpies calculated at $298.15 \mathrm{~K}$. Modified Arrhenius parameters for the coupling reactions are listed in Tables $1-3$ for the temperature range of $600-1200 \mathrm{~K}$ and Table 4 provides the corresponding average rate constant values ( $1000 \mathrm{~K})$.

Coupling reactions of $\boldsymbol{B}(\boldsymbol{C}) \boldsymbol{P R} 1$ with $2-B(C) P$. In this section, we focus our attention on the combination reactions of $\mathbf{B}(\mathbf{C}) \mathbf{P R} 1$ radicals with $2-\mathrm{B}(\mathrm{C}) \mathrm{P}$ molecules. Fig. $4 \mathrm{a}-\mathrm{d}$ illustrate the products of the radical/molecule coupling modes for BPR1/2-BP, BPR1/2-CP, CPR1/ $2-\mathrm{BP}$, and CPR1/2-CP, respectively. Owing to the geometrical similarity between BPR1 and CPR1, as well as that between 2-BP and 2$\mathrm{CP}$, the reactions of these four coupling modes exhibit similar mechanistic and kinetic characteristics. As shown in Fig. 4, attachments of the phenoxy oxygen atoms in B(C)PR1 at the ortho $\mathrm{C}(\mathrm{H})$ and ortho $\mathrm{C}(\mathrm{Cl}, \mathrm{Br})$ sites (denoted as $\mathrm{O} / / \mathrm{C}$ for short) produce ether-type intermediates IM1-IM6. The activation enthalpies of these coupling reactions are in a very narrow range of $22.3 \mathrm{kcal} / \mathrm{mol}$ to $23.0 \mathrm{kcal} / \mathrm{mol}$, which is consistent with the energy barriers (20.8-21.3 $\mathrm{kcal} / \mathrm{mol})$ encountered in the CPR1/2-CP combination reactions reported by Altarawneh et al. (2007). Formation of the halogenated diphenyl ether molecules (o-phenoxyphenol) IM2 and IM5 from combination of phenoxy $\mathrm{O}$ atoms with the ortho- $\mathrm{C}(\mathrm{Cl}, \mathrm{Br})$ sites is accompanied by a simultaneously expelling of a $\mathrm{Cl}$ or $\mathrm{Br}$ atom. Self-ejection of an $\mathrm{H}$ atom bound to the pivot carbon atom of the ether bridge from IM1, IM3, IM4 and IM6 also affords halogenated $o$-phenoxyphenol. Taking IM1 as an example, transformation of IM1 can eventually lead to the formation of 1monobromidibenzo-p-dioxin (1-MBDD) and 1,6-dibromidibenzop-dioxin (1,6-DBDD) and the reaction pathway is depicted in Fig. S1.
The elementary reaction processes involved in this route include intramolecular $\mathrm{H}$ elimination, phenolic $\mathrm{H}$ abstraction, and the ringclosure steps. Along the same line of inquiry, these initial combination intermediates IM2-IM6 all act as potent precursors of PXDDs (Altarawneh et al., 2007; Yu et al., 2011; Zhang et al., 2008).

Ortho $\mathrm{C}-\mathrm{C}$ cross linkages of $\mathbf{B}(\mathbf{C}) \mathbf{P R} 1$ with the $2-\mathrm{B}(\mathrm{C}) \mathrm{P}$ molecule (denoted as $\mathrm{C} / \mathrm{C}$ for short) produce four enol-keto adduct intermediates in each coupling mode, and thus, sixteen $\mathrm{C}-\mathrm{C}$ linkage intermediates (IM7-IM22) are formed in total. These enol-keto intermediates function as building blocks for furan structures. Formation of PXDFs from IM7-IM22 may follow the reaction steps involving $o(\mathrm{C})-o(\mathrm{C})$ cross-linkages, intramolecular expulsing of an $\mathrm{H}, \mathrm{Cl}$ or $\mathrm{Br}$ atom, cyclization, and self-elimination of a hydrogen or a halogen atom. The reaction enthalpies of the $\mathrm{C}-\mathrm{C}$ combination processes are estimated to be $20.7-35.4 \mathrm{kcal} / \mathrm{mol}$, and the activation enthalpies range from 28.2 to $40.2 \mathrm{kcal} / \mathrm{mol}$, which are generally higher than those of the $\mathrm{O} / / \mathrm{C}$ coupling reactions. Thus, it is evident that formation of $o$-phenoxyphenol intermediates is thermodynamically favored over the production of the enol-keto intermediates from combination reactions of $\mathbf{B}(\mathbf{C}) \mathbf{P R} 1$ with $2-\mathrm{B}(\mathrm{C})$ $\mathrm{P}$. Table 1 lists calculated rate constants for these coupling reactions between $\mathbf{B}(\mathbf{C}) \mathbf{P R} 1$ and $2-\mathrm{B}(\mathrm{C}) \mathrm{P}$, and Table 4 gives the average rate constants for the two coupling modes, i.e., for the $\mathrm{C} / / \mathrm{O}$ type and $\mathrm{C} / /$ C coupling reactions. Obviously, as shown in Table 4 , the average rate constant for the $\mathrm{C} / / \mathrm{O}$ type coupling reactions is approximately 42 times larger than that of the $\mathrm{C} / \mathrm{C}$ coupling reactions $\left(8.91 \times 10^{-20} \times \mathrm{cm}^{3} \bullet\right.$ molecule $^{-1} \bullet \mathrm{s}^{-1} \quad$ versus $2.09 \times 10^{-21} \mathrm{~cm}^{3} \bullet$ molecule $\left.{ }^{-1} \bullet \mathrm{s}^{-1}\right)$. In other words, the combination reactions of $\mathbf{B}(\mathbf{C}) \mathbf{P R} 1$ with $2-\mathrm{B}(\mathrm{C}) \mathrm{P}$ tend to occur via the phenolic oxygen sites and to produce halogenated 0 -phenoxyphenol intermediates, which eventually lead to the formation of PXDDs.

Coupling reactions of $\boldsymbol{P R 2}$ and $\boldsymbol{B}(\boldsymbol{C}) \boldsymbol{P R} 2$ with $2-B(C) P$. Owing to the exceedingly high reactivity of phenyl carbon sites, PR2 and B(C)PR2 may react with their parent molecules as soon as they are formed. The reaction pathways for couplings between BPR2 and 2-BP, between BPR2 and 2-CP, between CPR2 and 2-BP, between CPR2 and 2-CP, between PR2 and 2-BP, and between PR2 and 2-CP are depicted in Fig. 5a-f, respectively. Likewise, similar mechanistic and kinetic characteristics can be observed among these six coupling modes in Fig. 5. The phenyl radical sites in PR2 and $\mathbf{B}(\mathbf{C})$ PR2 attach to the ortho- $\mathrm{C}(\mathrm{H})$ positions of $2-\mathrm{B}(\mathrm{C}) \mathrm{P}(\mathrm{C} / / \mathrm{C}$ for short $)$ affording four adduct intermediates of IM23-IM28. Subsequent elimination of an $\mathrm{H}$ atom bound to the carbon-carbon bridges of structures IM23-IM28 create halogenated dihydroxybiphenyl molecules that serve as important precursors for PXDFs. While, attack of the phenyl radical sites at the ortho- $\mathrm{C}(\mathrm{Br}, \mathrm{Cl})$ positions of 2$\mathrm{B}(\mathrm{C}) \mathrm{P}$ with simultaneous extrusion of a halogen atom directly leads to the formation of halogenated dihydroxybiphenyl molecules IM29-IM31. As illustrated, these coupling reactions of PR2 and B(C)PR2 with 2-B(C)P are estimated to be exothermic by $16.4-31.5 \mathrm{kcal} / \mathrm{mol}$. Reactions involving the attachment to the ortho $\mathrm{C}(\mathrm{H})$ sites require slightly lower enthalpic barriers $(3.3-5.1 \mathrm{kcal} /$ $\mathrm{mol})$ than those involving the ortho $\mathrm{C}(\mathrm{Cl}, \mathrm{Br})$ sites $(7.0-9.5 \mathrm{kcal} /$ $\mathrm{mol})$. The difference in reaction barriers between these two types of reactions may originate from the potential steric hindrance caused by the voluminous size of $\mathrm{Cl}$ and $\mathrm{Br}$ atoms. However, all of these barriers are so trivial that they could be readily overcome even under ambient temperature conditions. Such a trivial activation barrier suggests that those coupling reactions involving the phenyl radicals may be competitive with the radical/radical combination reactions. Following the radical/molecule combination reactions, the initially formed intermediates IM23-IM31 can convert into various PXDF congeners. For instance, the reaction pathway for the formation of 4,6-bromdibenzofuran (4,6-DBDF) from IM23 is also 


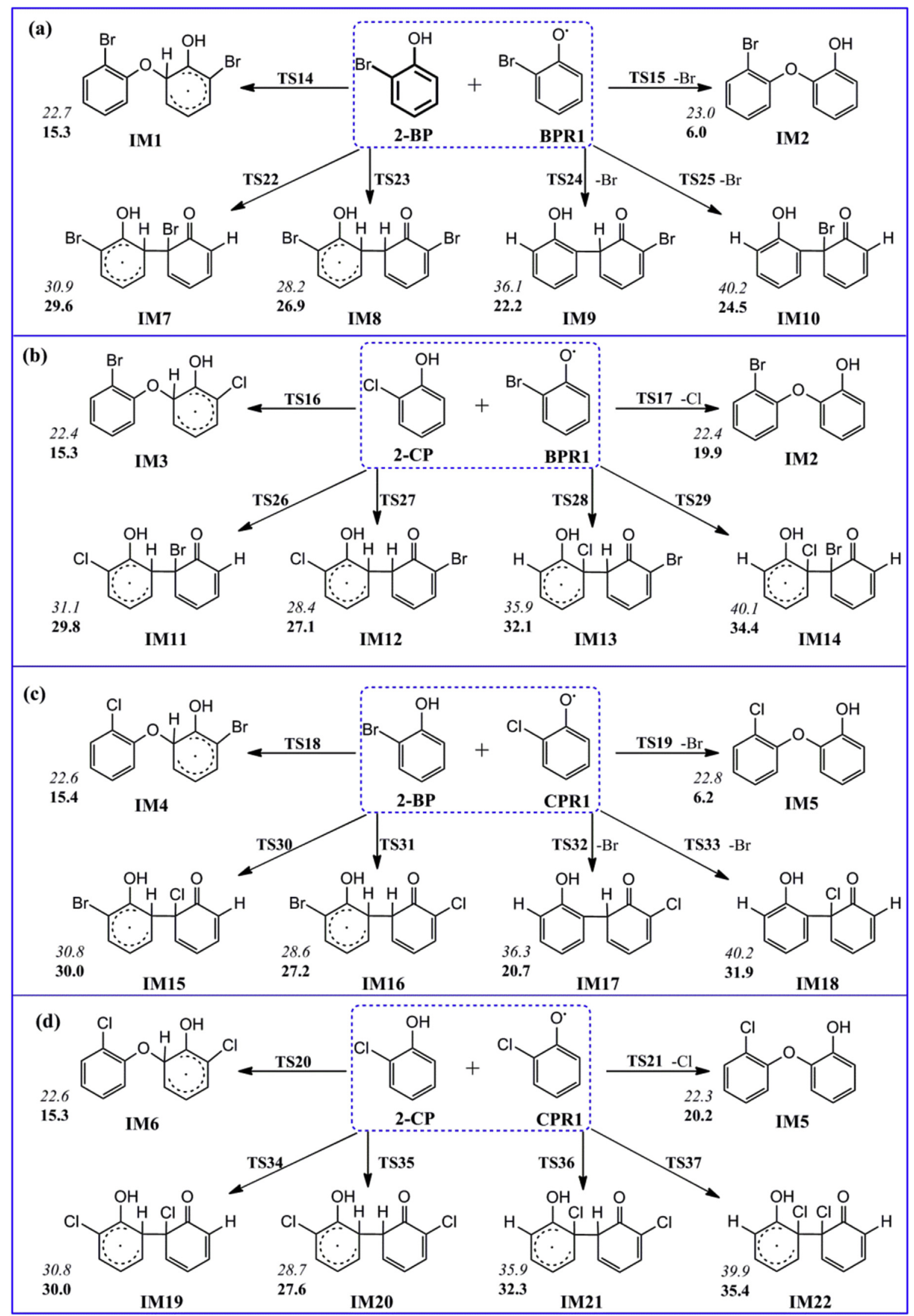

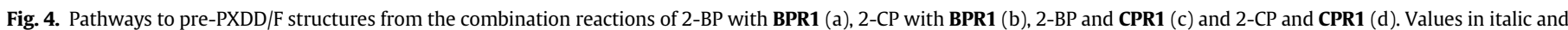
bold denote activation and reaction enthalpies, respectively. All values are in $\mathrm{kcal} / \mathrm{mol}$ calculated at $298.15 \mathrm{~K}$. 


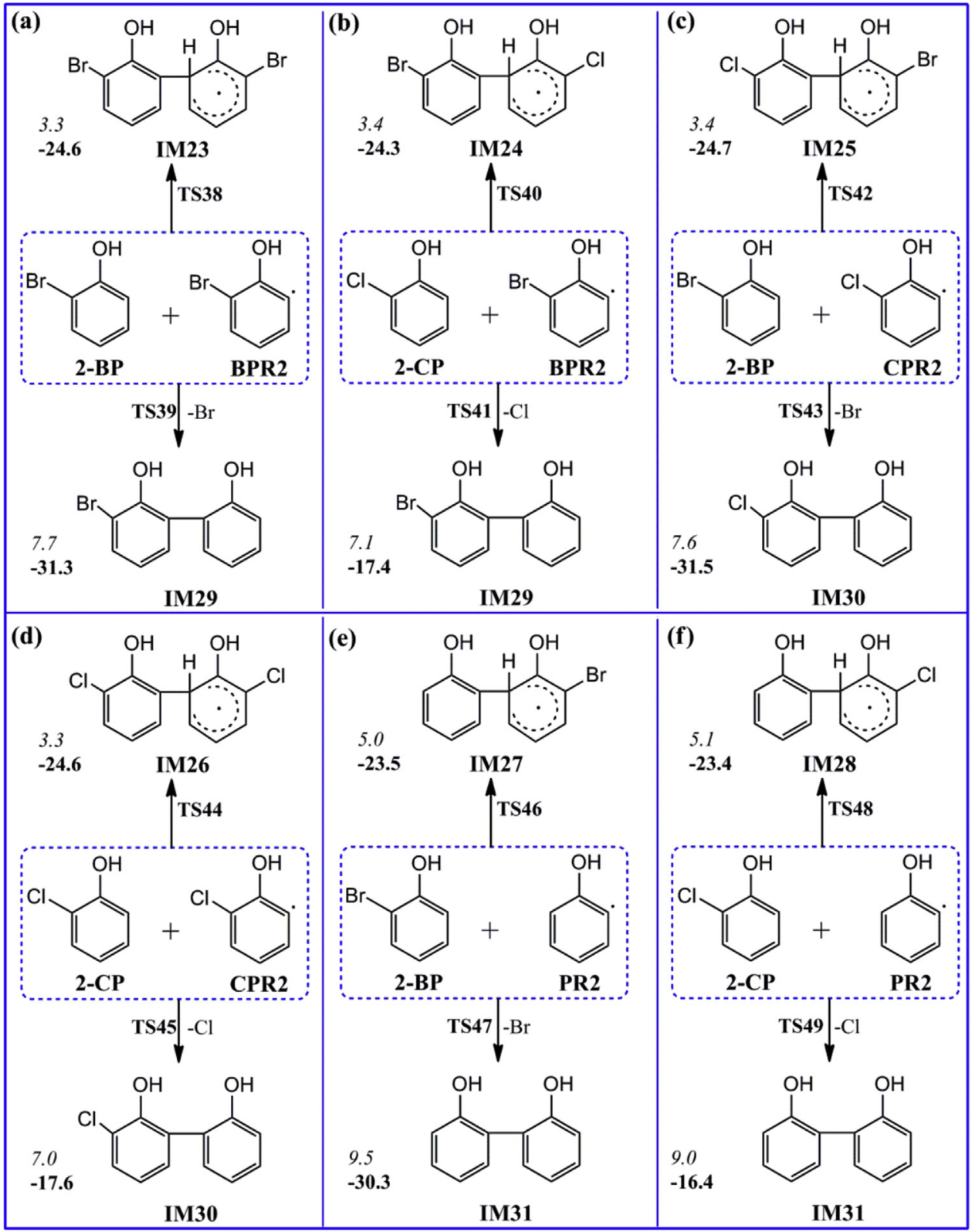

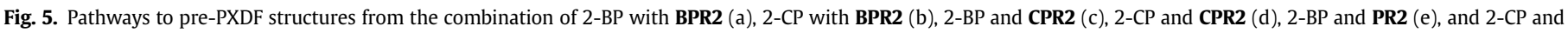
PR2 (f). Values in italic and bold denote activation and reaction enthalpies, respectively. All values are in $\mathrm{kcal} / \mathrm{mol} \mathrm{calculated}$ at $298.15 \mathrm{~K}$

given in Fig. S1.

Apparently, the two phenyl rings in the formed combination products would rotate around their corresponding $\mathrm{C}-\mathrm{C} / \mathrm{C}-\mathrm{O}$ linkages. To verify the obtained structure as a global minimum other than a local one, we have performed conformational analysis. Taken the intermediate structures IM1 and IM23 as examples, we calculated the relative energy diagram as a function of dihedral angle by performing partial optimization around their corresponding dihedral angles at an interval of $30^{\circ}$ at the $\mathrm{BB} 1 \mathrm{~K} / 6-311 \mathrm{G}(\mathrm{d}, \mathrm{p})$ level (Fig. S2). Obviously, the global minimum points of IM1 and IM23 locate at the dihedral angels about $270^{\circ}$, which concurs with our fully optimized structures at 263.5 and $263.1^{\circ}$, respectively. Based on this analysis, we confirm that our obtained structures are indeed global minima.

To better understand the reactivity of $\mathbf{P R 2}$ and $\mathbf{B}(\mathbf{C}) \mathbf{P R 2}$ radicals with 2-B(C)P molecules, the rate constants for these coupling reactions were calculated within temperature range of $600-1200 \mathrm{~K}$ (Tables 2 and 4). Obviously, the average rate constants for the combination reactions involving PR2 and B(C)PR2 with 2-B(C)P are vastly higher than those for the reactions between $\mathbf{B}(\mathbf{C}) \mathbf{P R 1}$ and 2$\mathrm{B}(\mathrm{C}) \mathrm{P}\left(4.16 \times 10^{-15} \mathrm{~cm}^{3} \bullet\right.$ molecule ${ }^{-1} \cdot \mathrm{s}^{-1}$ versus $8.91 \times 10^{-21}$ and $2.09 \times 10^{-21} \mathrm{~cm}^{3} \bullet$ molecule $\left.{ }^{-1} \bullet \mathrm{s}^{-1}\right)$. This fact provides a strong evidence that phenyl radicals can initiate feasible reactions for the formation of PXDFs. Additionally, the similar thermodynamic and kinetic parameters obtained from the cross-combination reactions between the radicals BPR2 and CPR2 with 2-BP as well as 2-CP molecule indicated little effects caused by the bromine or chlorine substituent on the production of PXDFs.

Coupling reactions of $\boldsymbol{P} \boldsymbol{R} 3$ and $\boldsymbol{B}(\boldsymbol{C}) \boldsymbol{P R} 3$ with $2-B(C) P$. In this section, the coupling reaction pathways between BPR3 and 2-BP, between BPR3 and 2-CP, between CPR3 and 2-BP, between CPR3 and 2-CP, between PR3 and 2-BP, and between PR3 and 2-CP are 


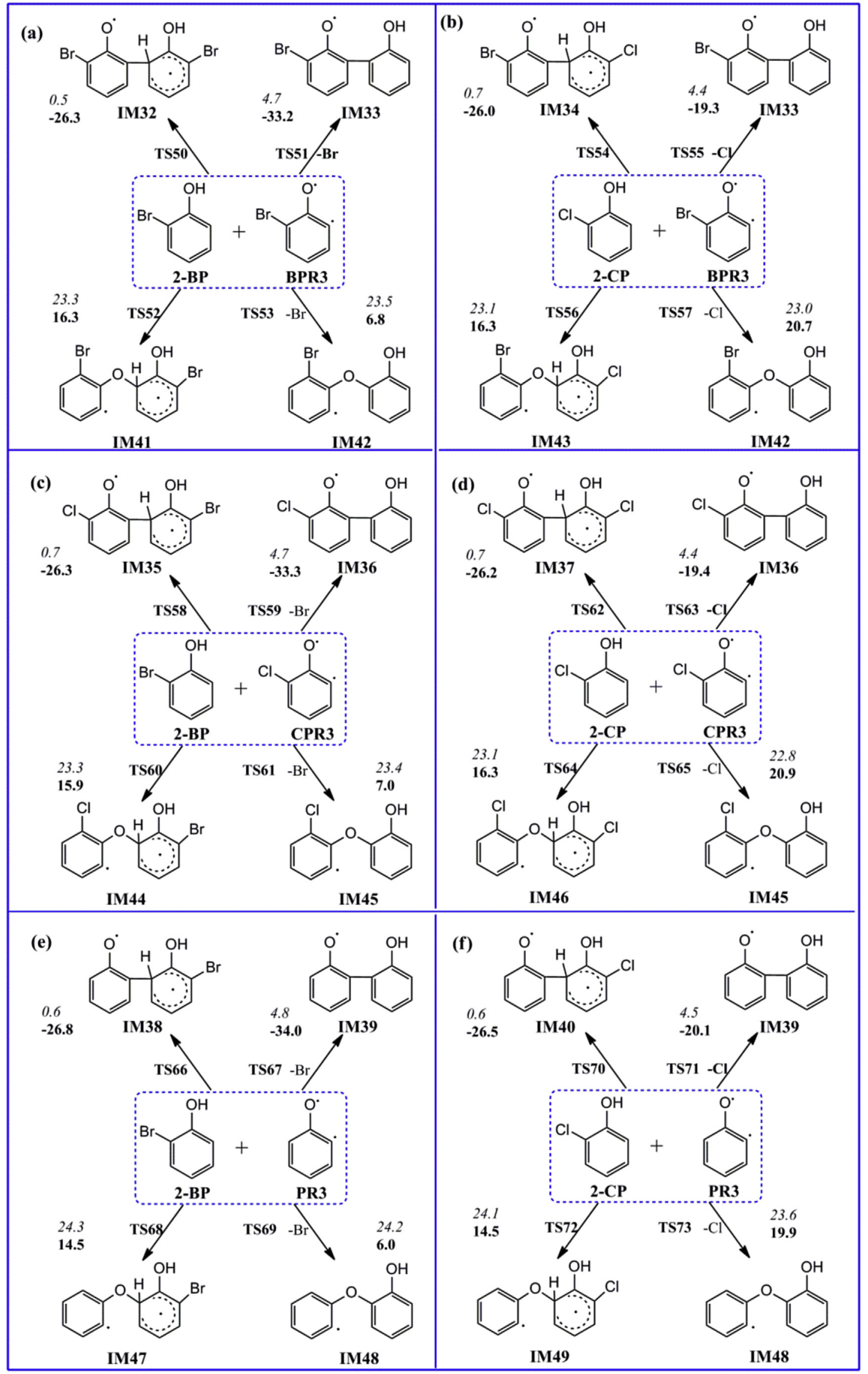

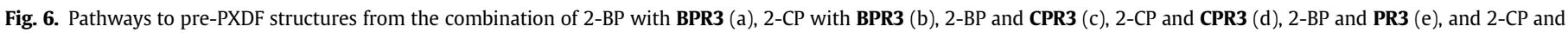
PR3 (f). Values in italic and bold denote activation and reaction enthalpies, respectively. All values are in $\mathrm{kcal} / \mathrm{mol} \mathrm{calculated}$ at $298.15 \mathrm{~K}$. 
Table 1

Fitted modified Arrhenius reaction rate parameters $(\mathrm{k}(T)=\mathrm{A} \exp (-E a / \mathrm{RT}))$ (between 600 and $1200 \mathrm{~K}$ ) for reactions of B(C)PR1 with 2-B(C)P.

\begin{tabular}{lll}
\hline Reaction & $\mathrm{A}\left(\mathrm{cm}^{3} \bullet\right.$ molecule $\left.^{-1} \bullet \mathrm{s}^{-1}\right)$ & $E a / \mathrm{R}(1 / \mathrm{K})$ \\
\hline $\mathrm{BPR} 1+2-\mathrm{BP} \rightarrow \mathrm{IM} 1$ & $5.95 \times 10^{-15}$ & 10,968 \\
$\mathrm{BPR} 1+2-\mathrm{BP} \rightarrow \mathrm{IM} 2+\mathrm{Br}$ & $1.09 \times 10^{-14}$ & 11,439 \\
$\mathrm{BPR} 1+2-\mathrm{CP} \rightarrow \mathrm{IM} 3$ & $1.07 \times 10^{-14}$ & 12,500 \\
$\mathrm{BPR} 1+2-\mathrm{CP} \rightarrow \mathrm{IM} 2+\mathrm{Cl}$ & $1.74 \times 10^{-14}$ & 12,773 \\
$\mathrm{CPR} 1+2-\mathrm{BP} \rightarrow \mathrm{IM} 4$ & $5.79 \times 10^{-15}$ & 10,890 \\
$\mathrm{CPR} 1+2-\mathrm{BP} \rightarrow \mathrm{IM} 5+\mathrm{Br}$ & $1.76 \times 10^{-15}$ & 9884 \\
$\mathrm{CPR} 1+2-\mathrm{CP} \rightarrow \mathrm{IM} 6$ & $2.03 \times 10^{-14}$ & 12,512 \\
$\mathrm{CPR} 1+2-\mathrm{CP} \rightarrow \mathrm{IM} 5+\mathrm{Cl}$ & $4.32 \times 10^{-14}$ & 12,707 \\
$\mathrm{BPR} 1+2-\mathrm{BP} \rightarrow \mathrm{IM} 7$ & $5.74 \times 10^{-15}$ & 15,300 \\
$\mathrm{BPR} 1+2-\mathrm{BP} \rightarrow \mathrm{IM} 8$ & $1.45 \times 10^{-14}$ & 13,940 \\
$\mathrm{BPR} 1+2-\mathrm{BP} \rightarrow \mathrm{IM} 9+\mathrm{Br}$ & $4.97 \times 10^{-15}$ & 17,727 \\
$\mathrm{BPR} 1+2-\mathrm{BP} \rightarrow \mathrm{IM} 10+\mathrm{Br}$ & $6.41 \times 10^{-16}$ & 18,884 \\
$\mathrm{BPR} 1+2-\mathrm{CP} \rightarrow \mathrm{IM} 11$ & $9.97 \times 10^{-15}$ & 17,076 \\
$\mathrm{BPR} 1+2-\mathrm{CP} \rightarrow \mathrm{IM} 12$ & $2.01 \times 10^{-14}$ & 15,720 \\
$\mathrm{BPR} 1+2-\mathrm{CP} \rightarrow \mathrm{IM} 13$ & $7.09 \times 10^{-15}$ & 19,083 \\
$\mathrm{BPR} 1+2-\mathrm{CP} \rightarrow \mathrm{IM} 14$ & $5.58 \times 10^{-16}$ & 20,236 \\
$\mathrm{CPR} 1+2-\mathrm{BP} \rightarrow \mathrm{IM} 15$ & $6.17 \times 10^{-15}$ & 15,102 \\
$\mathrm{CPR} 1+2-\mathrm{BP} \rightarrow \mathrm{IM} 16$ & $1.35 \times 10^{-14}$ & 14,077 \\
$\mathrm{CPR} 1+2-\mathrm{BP} \rightarrow \mathrm{IM} 17+\mathrm{Br}$ & $7.64 \times 10^{-15}$ & 17,791 \\
$\mathrm{CPR} 1+2-\mathrm{BP} \rightarrow \mathrm{IM} 18+\mathrm{Br}$ & $1.64 \times 10^{-15}$ & 19,536 \\
$\mathrm{CPR} 1+2-\mathrm{CP} \rightarrow \mathrm{IM} 19$ & $1.05 \times 10^{-14}$ & 16,811 \\
$\mathrm{CPR} 1+2-\mathrm{CP} \rightarrow \mathrm{IM} 20$ & $2.33 \times 10^{-14}$ & 15,865 \\
$\mathrm{CPR} 1+2-\mathrm{CP} \rightarrow \mathrm{IM} 21$ & $9.41 \times 10^{-15}$ & 19,127 \\
$\mathrm{CPR} 1+2-\mathrm{CP} \rightarrow \mathrm{IM} 22$ & $2.58 \times 10^{-15}$ & 20,889 \\
\hline
\end{tabular}

Table 2

Fitted modified Arrhenius reaction rate parameters $(\mathrm{k}(T)=\mathrm{A} \exp (-E a / \mathrm{RT}))$ (between 600 and $1200 \mathrm{~K}$ ) for reactions of PR2 and B(C)PR2 with 2-B(C)P.

\begin{tabular}{lll}
\hline Reaction & $\mathrm{A}\left(\mathrm{cm}^{3} \bullet\right.$ molecule $\left.^{-1} \bullet \mathrm{s}^{-1}\right)$ & Ea/R $(1 / \mathrm{K})$ \\
\hline $\mathrm{BPR} 2+2-\mathrm{BP} \rightarrow \mathrm{IM} 23$ & $2.45 \times 10^{-14}$ & 881 \\
$\mathrm{BPR} 2+2-\mathrm{BP} \rightarrow \mathrm{IM} 29+\mathrm{Br}$ & $1.18 \times 10^{-14}$ & 3107 \\
$\mathrm{BPR} 2+2-\mathrm{CP} \rightarrow \mathrm{IM} 24$ & $5.23 \times 10^{-14}$ & 2632 \\
$\mathrm{BPR} 2+2-\mathrm{CP} \rightarrow \mathrm{IM} 29+\mathrm{Cl}$ & $3.19 \times 10^{-14}$ & 4390 \\
$\mathrm{CPR} 2+2-\mathrm{BP} \rightarrow \mathrm{IM} 25$ & $3.88 \times 10^{-14}$ & 1068 \\
$\mathrm{CPR} 2+2-\mathrm{BP} \rightarrow \mathrm{IM} 30+\mathrm{Br}$ & $1.62 \times 10^{-16}$ & 3087 \\
$\mathrm{CPR} 2+2-\mathrm{CP} \rightarrow \mathrm{IM} 26$ & $5.47 \times 10^{-14}$ & 2591 \\
$\mathrm{CPR} 2+2-\mathrm{CP} \rightarrow \mathrm{IM} 30+\mathrm{Cl}$ & $2.45 \times 10^{-14}$ & 4342 \\
$\mathrm{PR} 2+2-\mathrm{BP} \rightarrow \mathrm{IM} 27$ & $5.53 \times 10^{-14}$ & 3558 \\
$\mathrm{PR} 2+2-\mathrm{BP} \rightarrow \mathrm{IM} 31+\mathrm{Br}$ & $3.93 \times 10^{-14}$ & 5774 \\
$\mathrm{PR} 2+2-\mathrm{CP} \rightarrow \mathrm{IM} 28$ & $1.28 \times 10^{-13}$ & 3573 \\
$\mathrm{PR} 2+2-\mathrm{CP} \rightarrow \mathrm{IM} 31+\mathrm{Cl}$ & $5.41 \times 10^{-14}$ & 5369 \\
\hline
\end{tabular}

discussed and the corresponding results are illustrated in Fig. 6a-f, respectively. In the case of the phenoxyl diradicals PR3 and $\mathbf{B}(\mathbf{C})$ PR3, two typical radical sites located at the phenoxy $\mathrm{O}$ atoms and the phenyl $\mathrm{C}$ atoms lead to two types of reaction pathways, i.e., $\mathrm{O} / / \mathrm{C}$ and $\mathrm{C} / \mathrm{C}$ coupling pathways. The $\mathrm{O} / / \mathrm{C}$ coupling reactions involve combinations of the phenoxyl $\mathrm{O}$ atoms with the ortho- $\mathrm{C}$ positions bearing a hydrogen or a halogen atom in $2-B(C) P$. As can be seen in Fig. 6 , the $0 / / C$ coupling pathways afford nine phenyl-type species IM41 - IM49 with nearly the same activation enthalpies $(\sim 23 \mathrm{kcal} /$ mol). While, by analogy to the phenyl-type structure 2-(2bromophenoxy)-phenyl, a potent intermediate for PBDF reported by Altarawneh and Dlugogorski (2015b), the intermediates IM41-IM49 also function as pre-structures for PXDFs. The couplings involving the phenyl $\mathrm{C}$ sites in PR3 and $\mathbf{B}(\mathbf{C}) \mathbf{P R} 3$ with 2-B(C)P ( $C / / C$ coupling pathways) give rise to nine $C-C$ bridging moieties IM32-IM40. These reactions proceed without encountering intrinsic barriers $(0.5-4.8 \mathrm{kcal} / \mathrm{mol})$. Obviously, a lower energy barrier is involved in the $\mathrm{C} / \mathrm{C}$ coupling reactions than that required in the $\mathrm{O} / / \mathrm{C}$ condensation reactions indicating that the $\mathrm{C} / \mathrm{C}$ coupling pathways are more favorable than the $\mathrm{O} / / \mathrm{C}$ pathways. Once these coupling intermediates were formed, it would followed by the elimination of $\mathrm{H}$, cyclization and $\mathrm{OH}$ intramolecular elimination
Table 3

Fitted modified Arrhenius reaction rate parameters $(\mathrm{k}(T)=\mathrm{A} \exp (-\mathrm{Ea} / \mathrm{RT}))$ (between 600 and $1200 \mathrm{~K}$ ) for reactions of PR3 and B(C)PR3 with 2-B(C)P.

\begin{tabular}{|c|c|c|}
\hline Reaction & $\mathrm{A}\left(\mathrm{cm}^{3} \bullet\right.$ molecule $\left.^{-1} \bullet \mathrm{s}^{-1}\right)$ & $E a / R(1 / K)$ \\
\hline $\mathrm{BPR} 3+2-\mathrm{BP} \rightarrow \mathrm{IM} 32$ & $2.95 \times 10^{-14}$ & -323 \\
\hline $\mathrm{BPR} 3+2-\mathrm{BP} \rightarrow \mathrm{IM} 33+\mathrm{Br}$ & $8.75 \times 10^{-15}$ & 1688 \\
\hline $\mathrm{BPR} 3+2-\mathrm{BP} \rightarrow \mathrm{IM} 41$ & $1.43 \times 10^{-14}$ & 11,444 \\
\hline $\mathrm{BPR} 3+2-\mathrm{BP} \rightarrow \mathrm{IM} 42+\mathrm{Br}$ & $2.99 \times 10^{-14}$ & 11,853 \\
\hline $\mathrm{BPR} 3+2-\mathrm{CP} \rightarrow \mathrm{IM} 34$ & $9.34 \times 10^{-14}$ & 1340 \\
\hline $\mathrm{BPR} 3+2-\mathrm{CP} \rightarrow \mathrm{IM} 33+\mathrm{Cl}$ & $8.83 \times 10^{-15}$ & 2862 \\
\hline $\mathrm{BPR} 3+2-\mathrm{CP} \rightarrow \mathrm{IM} 43$ & $3.15 \times 10^{-14}$ & 13,010 \\
\hline $\mathrm{BPR} 3+2-\mathrm{CP} \rightarrow \mathrm{IM} 42+\mathrm{Cl}$ & $1.60 \times 10^{-14}$ & 13,160 \\
\hline $\mathrm{CPR} 3+2-\mathrm{BP} \rightarrow \mathrm{IM} 35$ & $2.22 \times 10^{-14}$ & -262 \\
\hline $\mathrm{CPR} 3+2-\mathrm{BP} \rightarrow \mathrm{IM} 36+\mathrm{Br}$ & $7.60 \times 10^{-15}$ & 1666 \\
\hline $\mathrm{CPR} 3+2-\mathrm{BP} \rightarrow \mathrm{IM} 44$ & $3.06 \times 10^{-15}$ & 11,379 \\
\hline $\mathrm{CPR} 3+2-\mathrm{BP} \rightarrow \mathrm{IM} 45+\mathrm{Br}$ & $2.42 \times 10^{-14}$ & 11,736 \\
\hline $\mathrm{CPR} 3+2-\mathrm{CP} \rightarrow \mathrm{IM} 37$ & $3.27 \times 10^{-14}$ & 1282 \\
\hline $\mathrm{CPR} 3+2-\mathrm{CP} \rightarrow \mathrm{IM} 36+\mathrm{Cl}$ & $1.20 \times 10^{-14}$ & 3002 \\
\hline $\mathrm{CPR} 3+2-\mathrm{CP} \rightarrow \mathrm{IM} 46$ & $2.15 \times 10^{-14}$ & 12,980 \\
\hline $\mathrm{CPR} 3+2-\mathrm{CP} \rightarrow \mathrm{IM} 45+\mathrm{Cl}$ & $3.17 \times 10^{-14}$ & 13,095 \\
\hline $\mathrm{PR} 3+2-\mathrm{BP} \rightarrow \mathrm{IM} 38$ & $7.32 \times 10^{-14}$ & 1362 \\
\hline $\mathrm{PR} 3+2-\mathrm{BP} \rightarrow \mathrm{IM} 39+\mathrm{Br}$ & $2.49 \times 10^{-14}$ & 3351 \\
\hline $\mathrm{PR} 3+2-\mathrm{BP} \rightarrow \mathrm{IM} 47$ & $9.39 \times 10^{-14}$ & 13,585 \\
\hline $\mathrm{PR} 3+2-\mathrm{BP} \rightarrow \mathrm{IM} 48+\mathrm{Br}$ & $4.74 \times 10^{-13}$ & 13,849 \\
\hline $\mathrm{PR} 3+2-\mathrm{CP} \rightarrow \mathrm{IM} 40$ & $7.12 \times 10^{-14}$ & 1473 \\
\hline $\mathrm{PR} 3+2-\mathrm{CP} \rightarrow \mathrm{IM} 39+\mathrm{Cl}$ & $2.27 \times 10^{-14}$ & 3039 \\
\hline $\mathrm{PR} 3+2-\mathrm{CP} \rightarrow \mathrm{IM} 49$ & $5.17 \times 10^{-14}$ & 13,486 \\
\hline $\mathrm{PR} 3+2-\mathrm{CP} \rightarrow \mathrm{IM} 48+\mathrm{Cl}$ & $7.32 \times 10^{-14}$ & 13,484 \\
\hline
\end{tabular}

processes which then produce the final products PXDFs. Exemplar pathways leading IM32 and IM41 to the formation of 4,6-DBDF and 1,6-DBDF are illustrated in Fig. S1.

To gain a further insight into the contribution of these two types of reaction pathways, rate constants for reactions involving PR3 and $\mathbf{B}(\mathbf{C}) \mathbf{P R 3}$ with 2-B(C)P molecule were calculated; the fitted Arrhenius parameters in the temperature range between $600 \mathrm{~K}$ and $1200 \mathrm{~K}$ and the average rate constant $(1000 \mathrm{~K})$ are listed in Tables 3 and 4, respectively. Inspection of the data in Table 4, we can see the average rate constant for the $\mathrm{C} / / \mathrm{C}\left(k_{\mathrm{C} / / \mathrm{C}}\right)$ and $\mathrm{C} / / \mathrm{O}\left(k_{\mathrm{C} / / \mathrm{O}}\right)$ coupling pathways were $1.34 \times 10^{-14}$ and $9.70 \times 10^{-20} \mathrm{~cm}^{3} \bullet$ molecule ${ }^{-1} \bullet \mathrm{s}^{-1}$ at $1000 \mathrm{~K}$, respectively. This suggests that $\mathrm{C} / / \mathrm{O}$ coupling pathways were more difficult to happen than $\mathrm{C} / / \mathrm{C}$ combination pathways, because the difference between $k_{\mathrm{C} / / \mathrm{C}}$ and $k_{\mathrm{C} / / \mathrm{O}}$ was approximately 6 orders of magnitude. This result is in consistent with the lower activation barrier involved in the $\mathrm{C} / \mathrm{C}$ coupling pathways. Therefore, the $C / / C$ coupling pathways are the most important pathways in the reactions between PR3 and $\mathbf{B}(\mathbf{C}) \mathbf{P R} 3$ with 2-B(C)P molecule. Analogously, bromine or chlorine substituent may also have little effect on the combinations between the radicals PR3 and B(C)PR3 with $2-\mathrm{B}(\mathrm{C}) \mathrm{P}$, as the thermodynamic and kinetic parameters obtained from these combination reactions are quite similar, and thus the PXDF yields including PBDF, PCDF as well as PBCDF may have comparable proportions from the reactions between PR3 and $\mathbf{B}(\mathbf{C})$ PR3 with 2-B(C)P.

To investigate the influence of the pressure and temperature on the reactions, we calculated rate constants of several selected intramolecular $\mathrm{H}$ elimination and ring-closure reactions at the pressure range between $10^{-3}$ bar and $10^{3}$ bar and at the temperatures of $600,800,1000$, and $1200 \mathrm{~K}$, correspondingly. The results are presented in Fig. S3 and Table S2 in the supporting information. Apparently, the rate constants of these reactions are largely dependent on temperatures and independent on pressures, that is, these rate constants increase greatly with the temperature increasing, while only slightly arise with the increasing pressures at higher temperatures (1000 and $1200 \mathrm{~K}$ ).

In summary, this work presented initial pathways for the gas phase formation of PXDD/Fs via a radical/molecule mechanism. The 
Table 4

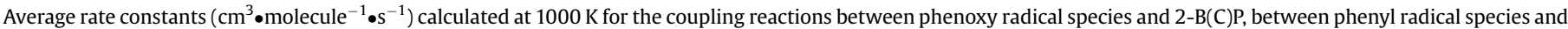

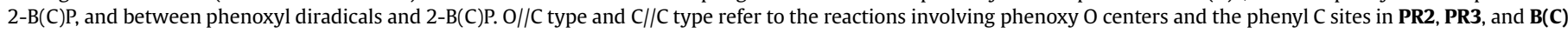
PR1-B(C)PR3, respectively.

\begin{tabular}{|c|c|c|c|c|}
\hline \multicolumn{2}{|c|}{ phenoxy radicals/2-B(C)P } & \multirow{2}{*}{$\begin{array}{l}\text { phenyl radicals } / 2-B(C) P \\
C / / C \text { type }\end{array}$} & \multicolumn{2}{|c|}{ phenoxyl diradicals/2-B(C)P } \\
\hline O//C type & C//C type & & $\mathrm{C} / / \mathrm{C}$ type & O//C type \\
\hline $8.91 \times 10^{-20}$ & $2.09 \times 10^{-21}$ & $4.16 \times 10^{-15}$ & $1.34 \times 10^{-14}$ & $9.70 \times 10^{-20}$ \\
\hline
\end{tabular}

coupling reactions of halogenated phenol molecules with halogenated phenoxy $\mathbf{B}(\mathbf{C}) \mathbf{P R} 1$ are more prone to occur through the phenoxylic oxygen atoms and produce halogenated $o$-phenoxyphenol, which are typical pre-intermediates of PXDDs. The condensation of substituted phenyl radicals PR2 and B(C)PR2 with brominated/chlorinated phenols on the phenyl carbon sites afford dihydroxybiphenyl species. The combination of pristine and substituted phenoxyl diradicals PR3 and B(C)PR3 with halogenated phenols yield two types of structures, i.e., dihydroxybiphenyl and $o-$ phenoxyphenyl, which act as building blocks for the formation of PXDFs. These condensation reactions, especially when they involve the phenyl radical sites in PR2, PR3, B(C)PR2 and $\mathbf{B}(\mathbf{C}) \mathbf{P R 3}$, are proven to be both thermodynamically and kinetically favorable and are comparable to radical/radical reactions. In particular, reactions involving the latter two types of radicals with halogenated phenols exclusively lead to the formation of PXDFs, which, to some extent, may provide a plausible explanation for the high PXDF:PXDD ratios in the real environment. Therefore, our study reveals that the radical/molecule mechanism should not be ignored in homogeneous gas-phase PXDD/F formation chemistry, especially in PXDF formation. The radical/molecule coupling patterns proposed in the present work fill in a knowledge gap that has hitherto existed regarding dioxin formation and improve our understanding of PXDD/F formation characteristics in the environment.

Based on the calculated results obtained above, we demonstrated the reactions of the phenyl radical and phenoxyl diradicals with phenol molecules would exclusively generate the less-toxic PXDFs. Future research needs to address the potential role of these two radical species on the formation of PXDD/Fs from other possible precursors such as 1,4-dihydroxybenzene (hydroquinone) and 1,2-dihydorxybenzene (catechol) in the bromine- and chlorinecontaining environment. Additionally, wide range of conditions such as thermal decomposition, hydrogen-rich and oxygen-rich combustion conditions should also be paid more attentions to investigate their possible influence on the formation of radical species and eventually the formation of PXDD/Fs.

\section{Notes}

The authors declare no competing financial interest.

\section{Acknowledgments}

This study was jointly supported by the National Natural Science Foundation $(21407167,21321004,21277164,21677168)$ and the Chinese Academy of Sciences (XDB14030500).

\section{Appendix A. Supplementary data}

Supplementary data related to this article can be found at http:// dx.doi.org/10.1016/j.envpol.2017.03.007.

\section{References}

Altarawneh, M., Dlugogorski, B.Z., Kennedy, E.M., Mackie, J.C., 2007. Quantum chemical investigation of formation of polychlorodibenzo-p-dioxins and dibenzofurans from oxidation and pyrolysis of 2-chlorophenol. J. Phys. Chem. A 111, 2563-2573.

Altarawneh, M., Radny, M.W., Smith, P.V., Mackie, J.C., Kennedy, E.M., Dlugogorski, B.Z., 2008. Adsorption of chlorophenol on the $\mathrm{Cu}(111)$ surfaces: a first-principles density functional theory study. Appl. Surf. Sci. 254, 4218-4224.

Altarawneh, M., Carrizo, D., Ziolkowski, A., Kennedy, E.M., Dlugogorski, B.Z Mackie, J.C., 2009a. Pyrolysis of permethrin and formation of precursors of polychlorinated dibenzo-p-dioxins and dibenzofurans (PCDD/F) under nonoxidative conditions. Chemosphere 74, 1435-1443.

Altarawneh, M., Dlugogorski, B.Z., Kennedy, E.M., Mackie, J.C., 2009b. Mechanisms for formation, chlorination, dechlorination and destruction of polychlorinated dibenzo-p-dioxins and dibenzofuran (PCDD/Fs). Prog. Energy Combust. Sci. 35, 245-274.

Altarawneh, M., Dlugogorski, B.Z., 2015a. Formation of polybrominated dibenzofurans from polybrominated biphenyls. Chemosphere 119, 1048-1053.

Altarawneh, M., Dlugogorski, B.Z., 2015b. Formation of dibenzofuran, dibenzo-pdioxin and their hydroxylated derivatives from catechol. Phys. Chem. Chem. Phys. 17, 1822-1830.

Altwicker, E.R., Milligan, M.S., 1993. Formation of dioxins: competing rates between chemically similar precursors and de novo reactions. Chemosphere 27, 301-307.

Bonnichon, F., Richard, C., Grabner, G., 2001. Formation of an $\alpha$-ketocarbene by photolysis of aqueous of 2-bromophenol. Chem. Commun. 73-74.

Canneaux, S., Bohr, F., Henon, E., 2014. KiSThelp: a program to predict thermodynamic properties and rate constants from quantum chemistry results. J. Comput. Chem. 35, 82-93.

Comandini, A., Malewicki, T., Brezinsky, K., 2012. Chemistry of polycyclic aromatic hydrocarbons formation from phenyl radical pyrolysis and reaction of phenyl and acetylene. J. Phys. Chem. A 116, 2409-2434.

Dickson, L.C., Lenoir, D., Hutzinger, O., 1992. Quantitative comparison of de novo and precursors formation of polychlorinated dibenzop-dioxins under simulated municipal solid waste incinerator postcombustion conditions. Environ. Sci. Technol. 26, 1822-1828.

Du, B., Zheng, M.H., Huang, Y., Liu, A., Tian, H.H., Li, L., Li, N., Ba, T., Li, Y., Dong, S. Liu, W., Su, G., 2010. Mixed polybrominate/chlorinated dibenzo-p-dioxins and dibenzofurans in stack gas emissions from industrial thermal processes. Environ. Sci. Technol. 44, 5818-5823.

Duan, H., Li, J., Liu, Y., Yamazaki, N., Jiang, W., 2011. Characterization and inventory of PCDD/Fs and PBDD/Fs emissions from the incineration of waste printed circuit board. Environ. Sci. Technol. 45, 6322-6328.

Evans, C.S., Dellinger, B., 2005. Formation of bromochlorodibenzo-p-dioxins and furans from the high-temperature pyrolysis of a 2-chlorophenol/2 bromophenol mixture. Environ. Sci. Technol. 39, 7940-7948.

Evans, C.S., Dellinger, B., 2006. Formation of bromochlorodibenzo-p-dioxins and furans from the high-temperature oxidation of a mixture of 2-chlorophenol and 2-bromophenol. Environ. Sci. Technol. 40, 3036-3042.

Frisch, M.J., Trucks, G.W., Schlegel, H.B., Scuseria, G.E., Robb, M.A., Cheeseman, J.R. Scalmani, G., Barone, V., Mennucci, B., Petersson, G.A., Nakatsuji, H., Caricato, M., Li, X., Hratchian, H.P., Izmaylov, A.F., Bloino, J., Zheng, G., Sonnenberg, J.L Hada, M., Ehara, M., Toyota, K., Fukuda, R., Hasegawa, J., Ishida, M., Nakajima, T., Honda, Y., Kitao, O., Nakai, H., Vreven, T., Montgomery Jr., Peralta, J.E., Ogliaro, F., Bearpark, M., Heyd, J.J., Brothers, E., Kudin, K.N., Staroverov, V.N., Keith, T. Kobayashi, R., Normand, J., Raghavachari, K., Rendell, A., Burant, J.C. Iyengar, S.S., Tomasi, J., Cossi, M., Rega, N., Millam, J.M., Klene, M., Knox, J.E. Cross, J.B., Bakken, V., Adamo, C., Jaramillo, J., Gomperts, R., Stratmann, R.E., Yazyev, O., Austin, A.J., Cammi, R., Pomelli, C., Ochterski, J.W., Martin, R.L. Morokuma, K., Zakrzewski, V.G., Voth, G.A., Salvador, P., Dannenberg, J.J., Dapprich, S., Daniels, A.D., Farkas, O., Foresman, J.B., Ortiz, J.V., Cioslowski, J. Fox, D.J., 2010. Gaussian 09, Revision B.01. Gaussian, Inc., Wallingford, CT.

Gao, R., Xu, F., Li, S., Hu, J., Zhang, Q., Wang, W., 2013. Formation of bromophenoxy radicals from complete series reactions of bromophenols with $\mathrm{H}$ and $\mathrm{OH}$ radicals. Chemosphere 92, 382-390.

Klippenstein, S.J., 2003. RRKM theory and its implementation. In: Green, N.J.B. (Ed.), Comprehensive Chemical Kinetics, vol 39. Elsevier, pp. 55-103.

Kumai, R., Matsushita, M.M., Izuoka, A., Sugawara, T., 1994. Intramolecular exchange interaction in a novel cross-conjugated spin system composed of $\pi$-ion radical and nitronyl nitroxide. J. Am. Chem. Soc. 116, 4523-4524.

Kumai, R., Sakurai, H., Izuoka, A., Sugawara, T., 1996. Ground state triplet cation diradicals having non-degenerated singly occupied molecular orbitals. Mol. Cryst. Liq. Cryst. 279, 133-138.

Li, S., Liu, W., Liu, G., Wang, M., Li, C., Zheng, M., 2015. Atmospheric emission of polybrominated dibenzo-p-dioxins and dibenzofurans from converter steelmaking processes. Aerosol Air Oual. Res. 15, 1118-1124.

Lomnicki, S., Truong, H., Dellinger, B., 2008. Mechanisms of product formation from 
the pyrolytic thermal degradation of catechol. Chemosphere 73, 629-633.

Louw, R., Ahonkhai, S.I., 2002. Radical/radical vs radical/molecule reactions in the formation of PCDD/Fs from (chloro)phenols in incinerators. Chemosphere 46, 1273-1278.

Luijk, R., Akkerman, D.M., Slot, P., Olie, K., Kapteijn, F., 1994. Mechanism of formation of polychlorinated-p-dioxins and dibenzofurans in the catalyzed combustion of carbon. Environ. Sci. Technol. 28, 312-321.

Luo, R.Y., 1999. Handbook of Bond Dissociation Energies in Organics. CRC Press Florida, Boca Raton.

Martinez, O., Crabtree, K.N., Gottlieb, C.A., Stanton, J.F., McCarthy, M.C., 2015. An accurate molecular structure of phenyl, the simplest aryl radical. Angew. Chem. Int. 54, 1808-1811.

McFerrin, C.A., Hall, R.W., Dellinger, B., 2009. Ab initio study of the formation and degradation reactions of chlorinated phenols. J. Mol. Struct. (THEOCHEM) 902, $5-14$.

Nganai, S., Lomnicki, S.M., Dellinger, B., 2011. Formation of PCDD/Fs from the copper oxide-mediated pyrolysis and oxidation of 1,2-dichlorobenzene. Environ. Sci. Technol. 45, 1034-1040.

Nganai, S., Dellinger, B., Lomnicki, S., 2014. PCDD/PCDF ratio in the precursor formation model over CuO surface. Environ. Sci. Technol. 48, 13864-13870.

Olsman, H., Engwall, M., Kammann, U., Klempt, M., Otte, J., van Bavel, B., Hollert, H. 2007. Relative differences in aryl hydrocarbon receptor-mediated response for 18 polybrominated and mix halogenated dibenzo-p-dioxins and -furans in cell lines from four different species. Environ. Toxicol. Chem. 26, 2448-2454.

Ortuno, N., Conesa, J.A., Molto, J., Font, R., 2014. De Novo synthesis of brominated dioxins and furans. Environ. Sci. Technol. 48, 7959-7965.

Pan, W., Zhang, D.J., Han, Z., Zhan, J.H., Liu, C.B., 2013. New insight into the formation mechanism of PCDD/Fs from 2-chlorophenol precursor. Environ. Sci. Technol. 47, 8489-8498.

Ryan, S.P., Altwicker, E.R., 2004. Understanding the role of iron chlorides in the de novo synthesis of polychlorinated dibenzo-p-dioxins/dibenzofurans. Environ. Sci. Technol. 38, 1708-1717.

Ryu, J.-Y., Mulholland, J.A., Kim, D.H., Takeuchi, M., 2005. Homologue and isomer patterns of polychlorinated dibenzo-p-dioxins and dibenzofurans from pheno precursors: comparison with municipal waste incinerator data. Environ. Sci. Technol. 39, 4398-4406.

Saeed, A., Altarawneh, M., Dlugogorski, B.Z., 2015. Formation of mixed halogenated dibenzo-p-dioxins and dibenzofurans (PXDD/Fs). Chemosphere 137, 149-156.

Samara, F., Gullett, B.K., Harrison, R.O., Clark, G.C., 2009. Determination of relative assay response factors for toxic chlorinated and brominated dioxins/furans using an enzyme immunoassay (EIA) and a chemically-activated luciferase gene expression cell bioassay (CALUX). Environ. Int. 35, 588-593.

Shi, X., Yu, W., Xu, F., Zhang, Q., Hu, J., Wang, W., 2015. PBCDD/F formation from radical/radical cross-condensation of 2-chlorophenoxy with 2-bromophenoxy, 2,4-dichlorophenoxy with 2,4-dibromophenoxy, and 2,4,6-tribromophenoxy. J. Hazard. Mater 295, 104-111.

Sidhu, S., Edwards, P., 2002. Role of phenoxy radicals in PCDD/F formation. Int. J. Chem. Kinet. 34, 531-541.

Söderström, G., Marklund, S., 2002. PBCDD and PBCDF from incineration of wastecontaining brominated flame retardants. Environ. Sci. Technol. 36, 1959-1964.

Stieglitz, L., 1998. Selected topics on the de novo synthesis of PCDD/PCDF on fly ash. Environ. Eng. Sci. 15, 5-18.

Wang, M., Liu, G., Jiang, X., Liu, W., Li, L., Li, S., Zheng, M., Zhan, J., 2015. Brominated dioxin and furan stack gas emissions during different stages of the secondary copper smelting process. Atmos. Pollut. Res. 6, 464-468.

Weber, R., Kuch, B., 2003. Relevance of BFRs and thermal conditions on the formation pathways of brominated and brominated-chlorinated dibenzodioxins and dibenzofurans. Environ. Int. 29, 699-710.

Wigner, E., 1937. Calculation of the rate of elementary association reactions. J. Chem. Phys. 5, 720-724.

Xiao, X., Hu, J., Peng, P., Chen, D., Bi, X., 2016. Characterization of polybrominated dibenzo-p-dioxins and dibenzo-furans (PBDDs/Fs) in environmental matrices from an intensive electronic waste recycling site, South China. Environ. Pollut. 212, 464-471.

Yasuharu, O., Mutsumi, T., 1999. Formation pathways from 2,4,5-trichlorophenol (TCP) to polychlorinated dibenzo-p-dioxins (PCDDs): an ab initio study. J. Phys. Chem. A 103, 7686-7691.

Yu, W., Hu, J., Xu, F., Sun, X., Gao, R., Zhang, Q., Wang, W., 2011. Mechanism and direct kinetics study on the homogeneous gas-phase formation of PBDD/Fs from 2-BP, 2,4-DBP, and 2,4,6-TBP as precursors. Environ. Sci. Technol. 45, 1917-1925.

Zhang, Q., Li, S., Qu, X., Shi, X., Wang, W., 2008. A quantum mechanical study on the formation of PCDD/Fs from 2-chlorophenol as precursor. Environ. Sci. Technol. 42, 7301-7308.

Zhang, Y.F., Zhang, D.J., Gao, J., Zhan, J.H., Liu, C.B., 2014. New understanding of the formation of PCDD/Fs from chlorophenol precursors: a mechanistic and kinetic study. J. Phys. Chem. A 118, 449-456.

Zhao, Y., Lynch, B.J., Truhlar, D.G., 2004. Development and assessment of a new hybrid density functional model for thermochemical kinetics. J. Phys. Chem. A 108, 2715-2719. 